\title{
A DUPLA HABILITAÇÃO NO CURSO DE LETRAS: IMPLICAÇÕES LIN- GUÍSTICAS E FORMADORAS
}

Elisandra Rios da Silva Pamponet DUARTE*

HÉLVIO FRANK DE OLIVEIRA**

\section{RESUMO}

Esta pesquisa objetiva problematizar aspectos inerentes à dupla habilitação obrigatória no curso de Letras da Universidade Estadual de Goiás, discutindo suas implicações linguísticas e formadoras para futuros professores de língua portuguesa e estrangeira (inglês). Um estudo de caso, apoiado em uma pesquisa documental e subsidiado por teorias de formação de professores de línguas (ALMEIDA FILHO, 2004; CELANI, 2010; PAIVA, 2003; 2004; 2005; QUADROS-ZAMBONI, 2015), foi conduzido, primeiramente, com formandos de 2017 de todos os campi da UEG que têm o curso de Letras (Português/Inglês) e, em um segundo momento, restringiu-se a especificidade a um desses campi instalado no interior goiano. Durante os estudos, percebemos que a habilitação dupla promove algumas (in)viabilidades em seu processo de formação docente, necessitando de reflexões críticas por parte das instâncias responsáveis pela elaboração das políticas de formação para que esse processo formativo se aperfeiçoe.

PALAVRAS-CHAVE: curso de Letras, dupla habilitação, formação docente.

\section{INTRODUÇÃO}

Estudos nas áreas de Educação e de Linguística Aplicada já discutiram a respeito da formação docente em cursos de Letras (ALMEIDA FILHO, 2004; CELANI, 2010; OLIVEIRA, 2013; 2016; entre outros). Entretanto, a dupla habilitação ainda é uma questão que,

* $\quad$ Mestra em Educação, Linguagem e Tecnologias pela Universidade Estadual de Goiás (UEG) Câmpus CSEH - Anápolis, Goiás, Brasil. E-mail: elisandra.rios@ueg.br.

** Doutor em Linguística pela Universidade Federal de Goiás (UFG), Goiânia, Goiás, Brasil. Pós-doutoral no PPGLA na Universidade de Brasília (UnB). E-mail: helviofrank@hotmail. com. 
além de pouco discutida (PAIVA, 2003; 2004; 2005; QUADROSZAMBONI, 2015), carece de reflexões linguísticas e formadoras, a fim de repensar a educação de professores para o ensino de duas línguas distintas.

Na condição de formadores de professores em cursos de Letras, a obtenção obrigatória de duas licenças estabelecida em algumas instituições nos inquieta. Alavancados pelo mercado de trabalho que, em sua competitividade, exige um modo de vida exemplar de concorrência, ter duas habilitações, enquanto normalmente se obtém apenas uma durante o mesmo período, corresponde a um critério promissor de seleção pessoal e profissional em nossos dias. No entanto, a lógica quantitativa geralmente não se confirma como garantia de um processo formador em que a qualidade em relação à aprendizagem e à formação em diferentes disciplinas/línguas ${ }^{1}$ se torne um fator profissional determinante.

A partir de uma experiência contextualizada, neste artigo buscamos problematizar aspectos inerentes à dupla habilitação obrigatória no curso de Letras, discutindo algumas possíveis implicações - linguísticas, pedagógicas e políticas - para a formação inicial de professores envolvendo as línguas portuguesa (doravante LP) e estrangeira (inglês) (doravante ILE). Para tanto, nas próximas linhas, apresentamos aspectos de ordem curricular, histórica e política acerca da formação docente em cursos de Letras no Brasil, em seguida, explicamos a metodologia de desenvolvimento de estudo, para, finalmente, discutirmos a pesquisa localizada.

\section{BREVE HISTÓRICO DOS CURSOS DE LETRAS NO BRASIL}

O primeiro curso de Letras no Brasil teve sua fundação na Universidade de São Paulo em 1934, com a instituição do Decreto ${ }^{\circ}$ 6.283/34. Tinha duração de três anos e a concepção de formação em mais de uma língua: Letras Clássicas/Português e Línguas Estrangeiras. Segundo Santos (2012), em 1940, implementou-se o ensino das línguas e literaturas espanholas, alemã e inglesa, e o curso passou a ser subdividido em Letras Clássicas, Letras Neolatinas e Letras AngloGermânicas. Até 1962, o estudante que optasse por uma das modalidades oferecidas, ao final do curso, tornava-se habilitado para lecionar várias 
línguas estrangeiras que estivessem incluídas em tal modalidade. Se, por exemplo, fossem as neolatinas, ele poderia lecionar português, latim, francês, espanhol e suas respectivas literaturas. Conforme Alvarez (2010), nesse período, o estudo de língua estrangeira era apenas um instrumento pelo qual os trabalhos com os textos literários ganhavam maior precisão, pois o curso tinha maior inclinação à reflexão poética, com suas abordagens estilísticas e filológicas, do que ao conhecimento pragmático da língua estrangeira.

Paiva (2005) destaca que, em 1962, houve uma reestruturação nos cursos de Letras por conta do Parecer Valnir Chagas $n^{\circ} 283$, aprovado pelo Conselho Federal de Educação, o qual instituiu a primeira proposta de um currículo mínimo para o curso. A nova proposta curricular previa o estudo de apenas uma língua estrangeira com sua respectiva literatura na modalidade da licenciatura dupla, enquanto a habilitação única era permitida apenas para a LP. Valnir Chagas achava inconcebível que um professor de língua estrangeira não tivesse também o domínio da língua materna e, por isso, não era autorizada a licenciatura única em língua estrangeira (PAIVA, 2003).

Diante da dificuldade de formar professor de língua estrangeira, devido à carga horária limitada de disciplinas, Santos (2012) lembra que, em 1966, o governo autorizou uma terceira opção para o curso de Letras, a habilitação única para língua estrangeira e respectiva literatura. Em 1969, as disciplinas de Didática, Psicologia e Prática de Ensino se tornam obrigatórias. Entretanto, em alguns contextos, são ministradas por profissionais pedagogos sem formação específica em língua estrangeira, Linguística e/ou Linguística Aplicada, o que, na concepção de Paiva (2003), contribui para a precariedade da formação do professor de língua estrangeira.

Finalmente, em 2001, são aprovadas as Diretrizes Curriculares Nacionais para os cursos

de Letras (DCNL) e de outros cursos de graduação através do Parecer CNE/CES 492/2001. O documento, que se constitui como um avanço no currículo, ao propor o desenvolvimento de competências e habilidades específicas ligadas à área de estudos linguísticos e literários, bem como a integração entre conteúdos básicos e de formação profissional, estabelece que 
o objetivo do Curso de Letras é formar profissionais interculturalmente competentes, capazes de lidar, de forma crítica, com as linguagens, especialmente a verbal, nos contextos oral e escrito, e conscientes de sua inserção na sociedade e das relações com o outro. Independentemente da modalidade escolhida, o profissional em Letras deve ter domínio do uso da língua ou das línguas que sejam objeto de seus estudos, em termos de sua estrutura, funcionamento e manifestações culturais, além de ter consciência das variedades linguísticas e culturais. Deve ser capaz de refletir teoricamente sobre a linguagem, de fazer uso de novas tecnologias e de compreender sua formação profissional como processo contínuo, autônomo e permanente. A pesquisa e a extensão, além do ensino, devem articular-se neste processo. O profissional deve, ainda, ter capacidade de reflexão crítica sobre temas e questões relativas aos conhecimentos linguísticos e literários. (BRASIL, 2001, p. 30).

A possibilidade de flexibilização curricular com vistas a melhor atender às diferentes necessidades de suas clientelas e às peculiaridades das regiões nas quais o curso se insere, sugerida pelas DCNL e também pela LDB, em 1996, contempla um dos objetivos e metas do Plano Nacional de Educação (2001-2010), em vigor naquele período. Todavia, a autonomia oferecida às universidades na proposição de seus cursos e na elaboração de seus currículos produzida pelas DCNL, conforme sublinha Quadros-Zamboni (2015), tenta disfarçar o seu teor tecnicista e instrumentalista de formação, ao sugerir o domínio de métodos e técnicas pedagógicas na transposição de conhecimentos (BRASIL, 2001).

\section{A DUPLA HABILITAÇÃO EM LETRAS}

Celani (2010) afirma que os resultados da formação inicial de professores de língua estrangeira têm sido decepcionantes por várias razões e uma delas é a possibilidade de dupla habilitação. A preparação do futuro docente de línguas, nesse caso, é prejudicada tanto em relação ao desenvolvimento da proficiência linguística quanto à discussão teórico-metodológica, os quais são quesitos fundamentais para a formação e a realização do estágio docente. Paiva $(2004,2005)$ também ressalta que a parte mais afetada, no que concerne à dupla habilitação 
com a estrutura do sistema 3 mais $1,{ }^{2}$ indicado pela Resolução CNE/ $\mathrm{CP} \mathrm{n}^{\mathrm{o}} 2 / 2002$, é a formação do professor de língua estrangeira, visto que, em grande parte dos cursos de Letras, as matrizes curriculares privilegiam os conteúdos relacionados à LP.

Sem uma legislação específica para cursos de Letras que decidem se configurar como dupla licenciatura, o período de duração de quatro anos e a integralização perfazendo o total de $2.800^{3}$ horas, que são bem similares aos de cursos de habilitação única, parecem confabular um risco qualitativo à formação do professor de língua estrangeira. Não obstante, o problema se alastra com o histórico de avaliações do curso, iniciado em 1995 pelo Exame Nacional de Cursos (ENC), de modo a enfatizar exclusivamente a área de LP. Apenas com a Portaria do INEP $n^{\circ}$ 260/2014 é que os conteúdos linguísticos, literários e de formação docente de língua estrangeira passaram a receber atenção e a se tornar objeto de avaliação do Exame Nacional de Desempenho dos Estudantes (ENADE), provocando reflexões pedagógicas sobre a qualidade de oferta.

Diante disso, seria interessante pelo menos fixar um percentual de horas mínimas para o trabalho com a língua estrangeira, que não fosse inferior à metade da carga horária total do curso. Assim, é sugerido que parte do conteúdo seja trabalhada envolvendo prática, uso e interação. Sobre esse assunto, Quadros-Zamboni afirma que

a supremacia das disciplinas de língua portuguesa e afins na formação do professor de inglês promove a ocupação de espaços que deveriam estar sendo preenchidos pela formação específica em língua inglesa, em termos teóricos e pedagógicos e essa lacuna formativa é, ao meu ver, extremamente prejudicial à formação do aluno-professor de língua inglesa. Justificá-la por meio do discurso de que compete ao professor o preenchimento dessa lacuna apenas através da formação contínua é fechar os olhos para uma realidade que há anos se arrasta e não se resolve. E isso exige, sem sombra de dúvida, a necessidade de um maior aprofundamento na discussão a respeito das questões voltadas à formação desse professor. (QUADROS-ZAMBONI, 2015, p. 120).

Uma questão central a ser considerada na formação em cursos de Letras, para Alvarez (2010), são os fundamentos teóricos e perfis 
curriculares. A "qualidade" dos licenciandos varia muito entre as universidades brasileiras. Principalmente no interior, deixa-se muito a desejar acerca do domínio linguístico do ILE, uma vez que o reduzido número de horas de exposição ao idioma torna branda a formação cultural envolvendo questões linguísticas e literárias. Tentativas apontadas por Oliveira e Figueiredo (2013), como programas de extensão e pesquisa, entre outros, paralelos à licenciatura, como PIBID, bolsas em prol da licenciatura etc., buscam reverter o efeito negativo da falta de tempo ao aumentar o volume de tarefas e o tempo de dedicação à língua estrangeira.

Paiva (2004) ressalta que o mínimo para o profissional de Letras é o domínio dos conteúdos elementares que irá ensinar na educação básica e dos procedimentos pedagógicos que envolvem a dinâmica. Pimenta e Lima (2012) alertam que as dimensões metodológica e prática não devem ficar apenas sob a responsabilidade das disciplinas de estágio, mas de todas, oferecendo conhecimentos e métodos para serem aplicados no exercício da docência. Para Oliveira (2016), conteúdos de linguagem e de ensino de linguagem se integram. Por essa razão, todos os componentes curriculares devem se valer do aspecto prático, sem a separação de aspectos pedagógicos (disciplinas voltadas à área de Educação) dos linguísticos (disciplinas da área de Linguística e Literatura).

Além da concepção pedagógica de formação, outra questão que altera o perfil curricular em cursos de Letras diz respeito à concepção de língua adotada pela instituição formadora. Nesse contexto, uma perspectiva social de linguagem pode se mostrar abundante, tendo em vista as diferentes situações comunicativas, dimensões discursivas, textuais, comunicativas etc., que embrenham questões pragmáticas envolvidas na situação comunicativa e de uso linguístico. Esses preceitos são estabelecidos por documentos oficiais de ensino de línguas, como PCN (BRASIL, 1998a; 1998b) e OCEM (BRASIL, 2006), e também pelas DCNL:

Domínio do uso da língua portuguesa ou de uma língua estrangeira, nas suas manifestações oral e escrita, em termos de recepção e produção de textos; reflexão analítica e crítica sobre a linguagem como fenômeno psicológico, educacional, social, histórico, cultural, po- 
lítico e ideológico; visão crítica das perspectivas teóricas adotadas nas investigações linguísticas e literárias, que fundamentam sua formação profissional; preparação profissional atualizada, de acordo com a dinâmica do mercado de trabalho; percepção de diferentes contextos interculturais; utilização dos recursos da informática; domínio dos conteúdos básicos que são objeto dos processos de ensino e aprendizagem no ensino fundamental e médio; domínio dos métodos e técnicas pedagógicas que permitam a transposição dos conhecimentos para os diferentes níveis de ensino. (BRASIL, 2001, p. 30)

Travaglia (2009) destaca que a concepção de linguagem/língua tem a capacidade de alterar em grande escala o modo de estruturar o trabalho pedagógico. Na mesma direção, Antunes (2009, p. 218) compreende que "o que e como ensinamos e avaliamos estão na dependência imediata das concepções que temos acerca do que é uma língua, de como funciona e a que fins se propõe". Por isso, ressaltamos a importância de uma reflexão mais aprofundada sobre tais concepções formadoras que se instituem no currículo de licenciatura.

Mesmo com a abordagem comunicativa na área de língua estrangeira e com o avanço dos estudos do texto e do discurso, as pesquisas de Souza et al. (2012) e de Zozzoli (2012) em cursos de Letras, por exemplo, constatam a presença de métodos tradicionais e gramaticais na formação do profissional de Letras. Mesmo com a irrupção da pedagogia crítica e da reflexão na formação, o ensino e a aprendizagem do professor de línguas ainda se mostram com procedimentos metodológicos técnicos e rígidos.

Três dimensões formadoras estabelecidas por Almeida Filho (2004) são distintivas ao professor de línguas: a profissional (relacionada à docência), a reflexiva (relacionada ao fazer docente em sala) e a comunicacional (relacionada ao instrumento língua). Por entre elas, diluem-se cinco competências básicas consideradas importantes para a formação do professor de línguas: linguístico-comunicativa, aplicada, teórica, implícita e profissional. Contudo, por entendermos que o contexto de formação - a universidade - acaba por reverberar o outro - a escola, acrescentamos, ainda, o caráter humanista, social e político integrado a essas dimensões, na tentativa de se educar linguisticamente na contemporaneidade. 


\section{Metodologia}

Este estudo se pauta no paradigma qualitativo de pesquisa proposto por Stake (2000), apoiando-se mais precisamente no método estudo de caso interpretativista. São também utilizados como referenciais teóricometodológicos os princípios da pesquisa documental (GIL, 2008) e a combinação de dados qualitativos e quantitativos (BRYMAN, 1995). $\mathrm{O}$ contexto inicial da pesquisa se concentrou em turmas pertencentes ao quarto ano de Letras de 15 campi da Universidade Estadual de Goiás no ano de 2017. Dessa fase, participaram 196 alunos, os quais, de forma voluntária, anônima e oficialmente consentida, responderam a questionários contendo perguntas abertas e fechadas, inerentes a assuntos socioeconômicos, a motivações e expectativas de ingresso no curso de Letras, bem como à condição de competências e afinidades nas línguas estudadas.

QUADRO 1 - MUNICÍPIOS GOIANOS QUE OFERECEM O CURSO DE LETRAS PELA INSTITUIÇÃO

\begin{tabular}{|c|c|}
\hline Municípios & Número de participantes \\
\hline Anápolis & 15 \\
\hline Campos Belos & 22 \\
\hline Formosa & 11 \\
\hline Goiás & 13 \\
\hline Inhumas & 7 \\
\hline Iporá & 11 \\
\hline Itapuranga & 6 \\
\hline Jussara & 10 \\
\hline Morrinhos & 13 \\
\hline Pires do Rio & 11 \\
\hline Porangatu & 25 \\
\hline Posse & 5 \\
\hline Quirinópolis & 10 \\
\hline São Luis de Montes Belos & 18 \\
\hline São Miguel do Araguaia & 19 \\
\hline Total de participantes & 196 \\
\hline
\end{tabular}

Fonte: Autora (2017). 
Depois, restringimos a geração de material empírico para apenas uma das turmas de formandos. Nessa etapa, contamos com dez acadêmicos voluntários, correspondendo a $50 \%$ da turma local, com os quais foi feita a entrevista semiestruturada. Algumas das perguntas previstas no roteiro geravam em torno de representações sobre a licenciatura, do grau de envolvimento com a profissão docente e das facilidades e dificuldades acerca das línguas de estudo, de ensino e de habilitação. Nesse último lócus de pesquisa, o curso de Letras (Português/Inglês) é ofertado em uma cidade de aproximadamente $23 \mathrm{mil}$ habitantes, no período noturno, sob regime curricular anual, totalizando quatro anos. Divide a demanda com três cursos de bacharelado, três outras licenciaturas e seis cursos tecnológicos, além da licenciatura em Pedagogia, oferecida pela própria universidade no turno matutino.

Além dos relatos produzidos pelos participantes, o material empírico gerado se constitui da leitura e análise de documentos legais de formação docente respectivos ao curso. Primamos pela abordagem interpretativa de triangulação das referidas fontes, a qual se balizou pela recorrência temática. A seguir, passamos à interpretação dos dados.

\section{INTERPRETAÇÃO DOS DADOS}

Nesta subseção, discutimos cinco categorias geradas em diálogo com o material empírico e teórico, a saber: o perfil discente, as questões curriculares de formação, as línguas-objeto de estudo, o nível de domínio das línguas e, por fim, as (in)viabilidades da dupla licenciatura para a aprendizagem, ensino e formação.

\section{O PERFIL DO ALUNO DE LETRAS (PORTUGUÊS/INGLÊS)}

Do contexto de pesquisa, $84 \%$ dos licenciandos em Letras são egressos da escola pública e outros $10 \%$ frequentaram a maior parte dos ensinos fundamental e médio em instituição financiada pelos governos municipal ou estadual. As mais variadas motivações de ingresso ao curso são: afinidade com as disciplinas do currículo, gratuidade e horário da oferta, localização geográfica do curso, melhoria de oportunidade e/ou de posição no mercado de trabalho, afinidade profissional e até mesmo a finalidade de simplesmente obter um diploma de ensino superior. 
[1] Eu escolhi o curso de Letras para ajudar o meu pai, analfabeto. Por ver a dificuldade com que ele se encontrava naquele tempo, optei por uma faculdade que me ajudasse a ensinar meu pai a ler. Sei que a Pedagogia se encaixava melhor, mas trabalho durante o dia e não dava para eu fazer, porque tenho que trabalhar. (Lara, questionário).

[2] Eu não tinha condições de mudar de cidade para fazer outro curso e, no momento, era a melhor opção para mim. Era o único curso noturno e gratuito oferecido na minha cidade. (Ana, questionário).

Apenas 16\% dos participantes indicaram a escolha do curso por afinidade profissional. Essa realidade, que pode ser resultado do alto índice de desvalorização da carreira na atualidade, desenha o perfil de "alguém desfavorecido em termos socioeconômicos, avesso ao risco e geralmente um aluno academicamente mediano" (ALVES et al., 2016, p. 18). Não obstante o pensamento elitista, é urgente que a docência seja objeto de interesse político, uma vez que as políticas profissionais são criadas, mas não executadas em prazo hábil, a exemplo do que está ocorrendo com as metas de valorização docente inclusas no Plano Nacional de Educação (2014-2024).

Ao mesmo tempo, os depoimentos nos fazem refletir sobre a relevância da interiorização do ensino superior, uma marca da instituição pesquisada, que tem 55\% (75 cursos) de oferta da modalidade de licenciatura no estado de Goiás, conforme dados do Processo Seletivo de 2018/1. Com a possibilidade de acesso, o aluno trabalhador pode optar por uma das 62 licenciaturas ofertadas no período noturno. Todavia, tempo e condições são cruciais para que as línguas estudadas ao longo do curso surtam o domínio de proficiência e fluência pessoal e profissional esperado.

$\mathrm{Na}$ amostra geral da instituição, percebe-se um perfil de formação jovem para o mercado de trabalho educacional, representado por $76 \%$ de graduandos com faixa etária de até 30 anos, 64\% se declarando solteiros, $72 \%$ pertencentes ao sexo feminino e apenas $31 \%$ inseridos no mercado de trabalho. Corroborando os resultados de estudos de Alvarez (2010) e de Oliveira (2013), os índices refletem o cenário contextual de um público trabalhador diurno, que perfaz mais de seis horas diárias em diferentes funções empregatícias (40\%), com apenas 
$17 \%$ dele envolvido profissionalmente com a docência, trabalhando em escolas ou ministrando aulas particulares de reforço.

Do ponto de vista pedagógico, os resultados denotam a conciliação discente entre trabalho e estudo, em que a dedicação ao curso, o envolvimento com projetos de pesquisa e de extensão e a própria aprendizagem das línguas ao longo da formação tornam-se o principal desafio. Especialmente em se tratando do esforço para a aprendizagem do ILE, o qual carece de tempo para exposição e para aprofundamento das dimensões linguísticas.

\section{O CURRÍCULO DE FORMAÇÃO DO PROFESSOR DE LÍNGUAS}

A dupla habilitação é opção obrigatória ao aluno que ingressa em um dos 15 cursos de Letras, cuja matriz curricular de disciplinas é unificada na universidade pesquisada. Em cumprimento a uma obrigatoriedade estabelecida pela LDB, de 1996, o curso de ensino superior habilita oficialmente para atuação profissional na segunda fase do ensino fundamental e no ensino médio, baseado na concepção de língua como fenômeno sociocultural e na realidade contextual do ensino desenvolvido de acordo com o Projeto Pedagógico do Curso (PPC).

O curso contempla uma carga horária total de 3.300 horas para integralização da sua matriz curricular, o que supera o mínimo exigido pela Resolução CNE/CP 2/2002. São 2.105 horas distribuídas para as disciplinas envolvidas diretamente com conteúdos relacionados às duas línguas, nos âmbitos linguístico, literário e pedagógico. Delas, 1.080 horas são relativas a disciplinas da área de LP, ao passo que 1.025 horas se destinam à área de ILE. Ainda que de modo tênue, a carga horária estabelecida caracteriza-se como déficit à última área.

[3] A carga horária da Língua Portuguesa é mais extensa, o que deixa o ensino de Língua Inglesa um pouco defasado. (Julliana B., questionário).

Os dados contidos no documento do curso se aproximam das constatações de Paiva (2003; 2005) e de Quadros-Zamboni (2015), quando também afirmam a superioridade de horas destinada à LP. 
Além disso, averiguamos que há uma compensação de horas para a área de LP, quando algumas disciplinas específicas da modalidade de licenciatura, trabalho de curso e atividades complementares (920 horas), de linguística (165 horas) e de teoria literária (110 horas), por exemplo, são ministradas ou exemplificadas em LP.

Mesmo havendo a supremacia de horas para as disciplinas direcionadas à área de LP, essa aprendizagem também não é uma garantia. A insuficiência de tempo de dedicação para estudar uma língua com riqueza de detalhes é um fator atenuante que incide sobre qualquer uma das línguas. Enquanto as dificuldades em relação ao ILE se concentram mais regularmente no desenvolvimento da competência comunicativa oral, a LP apresenta maiores rigores nas habilidades de comunicação escrita vislumbradas em produções de textos dos mais variados gêneros discursivos. Dessa forma, é comum o formando ter a sensação de que "não aprendeu a escrever" em LP ou de que "não sabe gramática", já na saída do curso. Logo, se a cultura de ensinar/aprender ILE remonta à modalidade oral, à modalidade escrita é reservado o sucesso da LP, e as cobranças sociais aparecem:

[4] Todo mundo que está fora acha que por estudarmos as duas línguas não podemos errar e temos de falar inglês fluentemente. (Nathy, questionário).

A prática como componente curricular das disciplinas voltadas à área de Literatura e de

Linguística do curso de Letras divide lugar com a teoria, para pensar o objeto teórico de ensino numa perspectiva de transposição didática, como se houvesse regularmente a condição de fazê-lo à medida que se ministram os conteúdos. Ou seja, a carga horária das disciplinas é explicitamente dividida entre teórica e prática. Tornam-se exceções apenas as disciplinas da modalidade de orientação de estágio, que informam exclusivamente a carga teórica, e as de estágio, definidas como práticas. Com essa divisão de ordem teórica e prática, acabam por denunciar o gargalo da racionalidade técnica sobre o currículo de formação ao representarem equivocadamente o que deveria ser, por essência, diluído. 
Como podemos ver no gráfico abaixo, a LP se mostra como objeto de preferência e de identificação pelos participantes:

GrÁFICO 1 - MAIOR IDENTIFICAÇÃo PROFISSIONAL EM TERMOS DE LÍNGUA

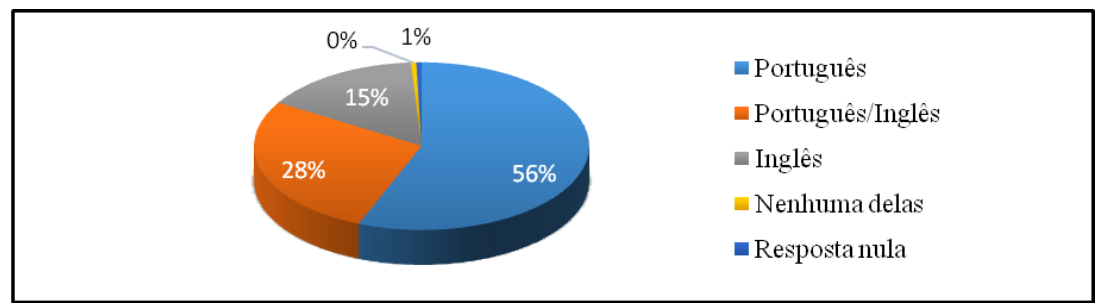

Fonte: Autora (2017).

$\mathrm{O}$ fato de alguns participantes não se identificarem com as duas línguas provoca insatisfação e acaba por gerar antipatia pela área que não lhes é de interesse.

[5] Não é vantajosa [a dupla licenciatura], pois há quem não tem afinidade com uma nova língua, o que acaba causando antipatia. (Capitu, questionário).

Considerando que a motivação é um fator decisivo para a aprendizagem de línguas (GARDNER, 1985), uma vez que ela se torna um dispositivo influenciador do interesse para buscar o conhecimento, de igual modo a falta de afinidade pode trazer prejuízo ao processo, por inverter a relação. $\mathrm{Na}$ dupla habilitação obrigatória, o efeito que transparece na prática é a identidade profissional-pessoal por uma língua e a sujeição à outra.

\section{NÍVEL DE DOMÍNIO DAS LÍNGUAS}

O Gráfico 2 apresenta a consideração discente sobre o nível de domínio de LP e ILE. Nele, é evidente o melhor desempenho relacionado àquele idioma: 
GráFico 2 - Nível DE DOMíNIO DAS LíNGUAS DE HABILITAÇÃo

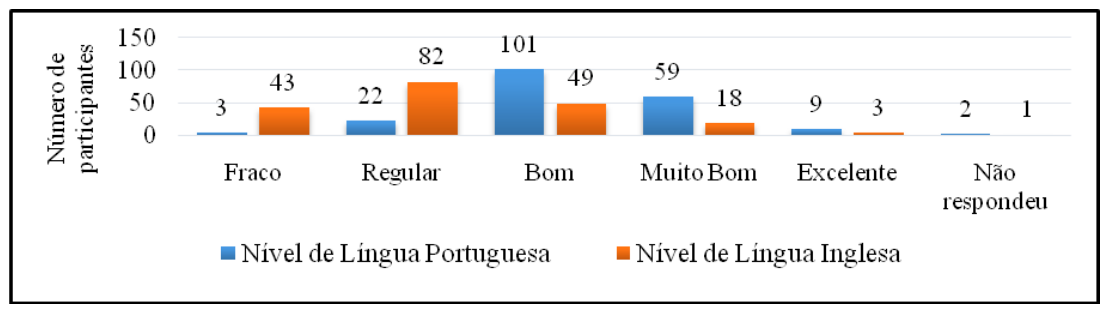

Fonte: Autora (2017).

Enquanto, para os menores índices de domínio linguístico equivalentes ao da (não) aprendizagem satisfatória de ILE, os alunos justificam a insuficiência do tempo durante a graduação, em relação aos melhores níveis, são atribuídos os fatos de motivação pessoal e de tempo de dedicação para a aquisição do idioma anteriores à universidade:

[6] [Meu nível de LE (inglês) é regular] Porque, infelizmente, o tempo destinado ao estudo da língua inglesa dentro do curso não é suficiente para nossa formação. (Ana, questionário).

[7] [Meu nível de LE (inglês) é muito bom] Primeiramente, porque, antes de me ingressar no curso de Letras, fiz cursinho por volta de 6 anos no FISK. Então, tenho um maior domínio. (Letícia R., questionário).

[8] [Meu nível de LE (inglês) é muito bom] Eu tenho muita dedicação à língua inglesa e estudo muito em casa o que aprendo na faculdade. (Cida, questionário).

Duda aciona uma reflexão pertinente sobre a perspectiva de duas realidades bastante comuns nos cursos de Letras pesquisados no que tange à formação: a chegada de alunos sem domínio de ILE.

[9] Tem a questão que alguns falam de que é pouco tempo para ensinar as duas línguas, mas o certo é que nós deveríamos já vir para o curso sabendo, aí os professores facilitam, ensinando o que tínhamos que ter aprendido. E aqui o foco não era esse, não é? $\mathrm{O}$ foco aqui no curso não era ensinar o conteúdo que vamos ensinar, mas a forma de como nós podemos ser professores. $\mathrm{O}$ foco aqui era 
ensinar como eu vou ser, como eu vou ensinar a gramática ali na sala de aula, por exemplo, é formar realmente professores e não ensinar o conteúdo que deveria ter ensinado no ensino médio. (Duda, entrevista).

A participante discute o fato de cursar Letras para aprender a ensinar o ILE, enquanto, na realidade, o que ocorre, primeiramente, é a busca pela aprendizagem da língua.

[10] Tenho dificuldade na língua inglesa, pois não vim com uma base boa para a universidade. [...] A maior desvantagem é a dificuldade da língua inglesa no curso, pois a grande maioria dos alunos não tem uma base boa para assim compreender e sair com uma base melhor para futuros professores de língua inglesa. (Sue, questionário).

Quando o curso de Letras ocupa-se do preenchimento das lacunas de aprendizagem de ILE, que se arrastam desde a educação básica, a formação docente, caracterizada pelos procedimentos pedagógicos, didáticos e reflexivos de transposição de conteúdo, perde grandes chances de trabalho e de aprofundamento. Com isso, o tempo reservado aos processos formativos de aprimoramento técnico, pedagógico e profissional é repartido com a tentativa de aprendizagem mínima da língua que se pretende futura e profissionalmente ensinar.

A falta de domínio de ILE não é exclusiva do contexto de dupla habilitação pesquisado. Do contrário, se houvesse a possibilidade de escolha de habilitação, uma vez que a educação linguística envolve motivação, identificação, entre outros processos, algumas características vislumbradas neste estudo poderiam se reverter na qualidade do processo, a fim de assegurar uma formação mais consubstanciada em conteúdos e conhecimento de linguagem. Dentro da complexidade que abriga os cursos de Letras, com ou sem dupla habilitação, não podemos excluir aquele que realmente deseja aprender o ILE. Igualmente, não podemos mantê-lo numa dupla habilitação em que uma das línguas, de certa forma, exclui-o da formação docente desejada. Porque esta também pode se constituir como uma ação de interesse ou desinteresse, de investimento ou de desgaste emocional. A aversão à língua, além de se configurar como aspecto negativo para a aprendizagem linguística, também resvala consideravelmente no trabalho profissional. 
[11] Eu avalio [meu domínio de LP] como bom. Me ajudou muito, esclareceu muitas dúvidas e levo uma boa bagagem para o campo profissional. Em língua inglesa, excelente. Sou apaixonada! Aprendi tanto que eu quero ser professora de língua inglesa. No curso, o que mais me chamou a atenção, o que foi o ponto principal para mim, foi o inglês. [...] Foram muito boas as práticas pedagógicas desenvolvidas durante os quatro anos do curso. Então, ajudou muito a gente no desempenho da língua inglesa. (Cris, entrevista).

O fato de ser fluente nas habilidades da língua para a qual se forma soa como aspecto positivamente essencial, uma vez que, junto da caracterização de domínio, vêm imprimidas as virtudes de motivação, interesse, empenho etc. Ninguém aprende/adquire aquilo por que não se interessa, que não se constitui em si mesmo como identidade. Se língua é cultura, é identidade, essa construção permeia a aprendizagem linguística e também profissional.

[12] [Nível bom de LP] Sinto-me mais confortável em trabalhar com a minha língua materna. (Yasmim, questionário).

Os participantes da pesquisa apresentaram suas potencialidades de formação ao longo da dupla habilitação, conforme o Gráfico 3:

Gráfico 3 - Potencial De modalidades DE CONTEÚdos ADQuiridos DURANTE O CURSO DE LETRAS

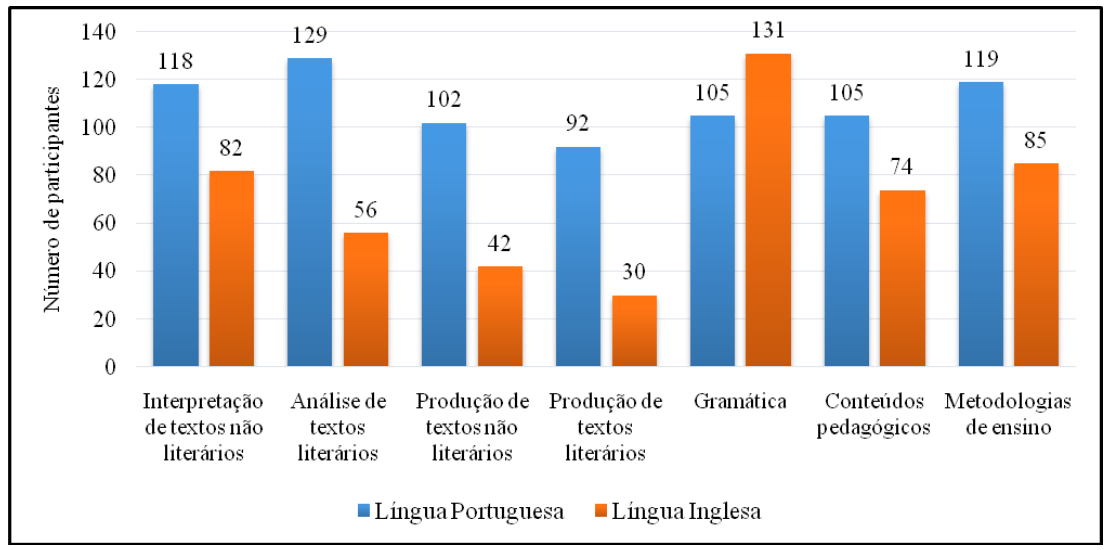

Fonte: Autora (2017). 
$\mathrm{Na}$ prática formadora, os alunos informam, de maneira bem sintética, características que configuram a cultura de aprendizagem de cada língua: na LP, é dedicado maior tempo ao trabalho literário; no ILE, a formação se dá por intermédio da transposição de métodos e metodologias. Além disso, com exceção do aspecto gramatical, há mais êxitos de aprendizagem sobre configurações de elementos vinculados à LP, o que nos permite inferir a ineficiência da prática do método gramática-tradução, muito utilizado em ambientes de aprendizagem de ILE, em detrimento de uma abordagem comunicativa.

[13] [Após entrar no curso de Letras] Eu consigo entender mais a língua universal que está presente em quase tudo na vida. No entanto, eu consigo traduzir e interpretar melhor essa língua. Infelizmente na parte oral não tenho facilidade em me comunicar. (Monique, questionário).

Efetivamente, a formação do professor de ILE é a que sinaliza mais relatos sobre dificuldades de aprendizagem. Talvez, por essa razão, as pesquisas sobre dupla licenciatura em Letras sejam mais corriqueiras nas áreas de Linguística Aplicada e não de Linguística.

\section{ALGUMAS (IN)VIABILIDADES EM TORNO DA FORMAÇÃO PARA DUAS LÍNGUAS}

A lógica capitalista e competitiva mundial contorna uma das principais viabilidades da dupla habilitação em Letras observada no estudo: a ampliação de oportunidades no mercado de trabalho, seja para atuar nas duas línguas, seja para escolher entre uma delas:

[14] Após a formação, é possível trabalhar com duas habilitações, e, assim, o fato de atuar em duas disciplinas favorece duas possibilidades de trabalho. (Mary, questionário).

[15] [A dupla habilitação permite] Poder lecionar em mais de uma disciplina, uma vez que a carga horária de línguas estrangeiras modernas, como o inglês, é bem reduzida. (Rafael, questionário).

Seguidas do teor capitalista, estão também outras viabilidades de aprendizagem de ILE apontadas em coro pelos participantes: 
[16] A vantagem é, claro, a abertura em dobro do mercado de trabalho, da ampliação do conhecimento teórico e prático. Outra vantagem é aprender uma língua universal "Inglês", ter facilidade ao acessar a internet, que tem muito dessa língua, além de ampliar a capacidade de escrita e leitura. (Cora, questionário).

[17] Maior capacitação, oportunidade de aprender outro idioma gratuitamente. Melhoria da capacidade mental, maior aprendizado, mais chances no mercado de trabalho. (Letras\#R, questionário).

Salta aos nossos olhos o discurso de Monique, no excerto 13, e de Cora, no excerto 16, evidenciando a noção de inglês como língua universal. Infelizmente, para essas futuras professoras, o ideal iluminista de criação de uma língua neutra, estática, artificial, desprovida de aspectos culturais, surgido no século XVIII, ainda se mostra bastante presente em suas visões sobre ILE e, consequentemente, sobre suas práticas. Nesse caso, vale a reflexão sobre possíveis implicações de tais acepções.

Paradoxalmente, como mostra o Gráfico 4, uma parcela significativa dos participantes se julga profissionalmente apta para lecionar apenas LP (38\%), e nos 32\% que, a princípio, se ancoram no interesse pelas duas línguas, notamos que o argumento de seus depoimentos se mantém concentrado na justificativa de possibilidade em escolher uma língua em detrimento do fracasso de atuação em outra, e não o argumento de atuação concomitante nas duas habilitações.

GráFICO 4 - APtidẽo PROFISSIONAL DOCENTE PARA AS LÍNGUAS

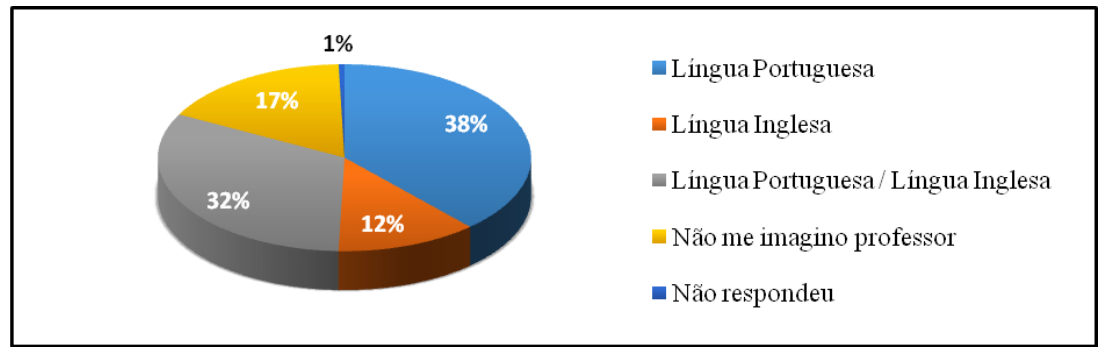

Fonte: Autora (2017). 
O desafio da habilitação bônus em cursos de Letras reside na qualidade pedagógica e profissional de sua oferta. Ter duas habilitações é, do ponto de vista quantitativo, algo satisfatório, mas pode ser qualitativamente prejudicial à formação docente por conta da complexidade que há em, durante a licenciatura, aprender especialmente o ILE, como discutiram Celani (2010) e Paiva (2004; 2005) e com novas incursões de fatores destacados neste estudo: tempo, motivação etc.

[18] Teve um momento no estágio de inglês que um dos alunos me perguntou assim: - Professora, mas você quer ser professora de inglês ou português? Até porque ele já tinha me visto na sala dele como professora de português em outro dia de estágio. Eu falei: Olha, se for para eu escolher a que eu teria mais vocação, a que eu tenho mais domínio, eu diria que de português. Não porque eu não goste do inglês, mas é porque ele exige uma preparação melhor. Eu, no exato momento, não me sinto preparada o suficiente, porque eu penso assim: a partir do momento que você pega uma disciplina para desenvolvê-la, você tem que ser boa naquilo que faz, você tem que dar o seu melhor. Então, no momento, o inglês seria um segundo plano. [...] [Se depois de formada] me oferecessem, e eu tiver mais... eu diria... não tempo, porque quem faz o tempo é a gente. Eu diria que, se eu tivesse oportunidade de melhorar o inglês, é claro que eu aceitaria dar aula. (Susy, entrevista).

[19] Mesmo o curso sendo de quatro anos, não sinto segurança em atuar nas duas áreas. Acho que ainda faltou conteúdo e suporte para exercermos a função de professores. (Kely, questionário).

Para Quadros-Zamboni (2015, p. 72), “apesar de o aprendizado de um idioma não ocorrer somente nos cursos de Letras, formar professores de língua inglesa que conheçam efetivamente o idioma é, há tempos, o Santo Graal que instituições, pesquisadores e formadores vêm perseguindo". Não raras vezes, as dificuldades na aprendizagem de ILE comprometem a projeção profissional. A questão intrigante é que as lacunas de aprendizagem de ILE presentes, identificadas pelos licenciandos, surgem sempre abastecidas pelo discurso da busca futura por aperfeiçoamento: 
[20] Vou sair da universidade preparada apenas para ser professora de língua portuguesa. Para ser professora de inglês, será necessário fazer um cursinho de aperfeiçoamento. (Sofia, questionário).

[21] Como professor[a] de português, eu conseguiria, sim, ter mais domínio do conteúdo, apesar de ser bem extenso. Mas eu conseguiria me adaptar melhor e ser um bom profissional dentro da sala de aula sendo uma professora de língua portuguesa. De língua inglesa, é igual eu falei anteriormente, eu acho que eu teria que doar mais de mim e procurar um conhecimento fora. Assim, apesar da faculdade nos dar esse pontapé inicial dentro desses quatro anos que a gente tem a língua inglesa no curso, eu acho que eu teria que me doar mais e buscar mais. (Beatriz, entrevista).

É muito comum a pretensão de aprimoramento da lacuna nunca ocorrer efetivamente por ocasião das várias atribuições do professor em serviço. Não obstante, a habilitação lambuja se torna efetiva e institucionalmente utilizada para o acréscimo de aumento de carga horária e de salário. O resultado, como já problematizou Oliveira (2013), é desolador e reflete os índices cíclicos de não aprendizagem de ILE nos ensinos fundamental e médio em que, no máximo, o professor, sob o "faz de conta", restringe a aprendizagem de ILE a estruturas gramaticais, consideradas uma ação didática de domínio mais simples por não focar em situação de uso linguístico e comunicação.

[22] Apesar da timidez, pretendo ser uma professora que não ensina apenas as regras gramaticais, mas que, além disso, ensine a analisar de uma forma não tão rasa, mas que também leve o aluno a refletir. (Capitu, questionário).

A sedução capitalista permitida pela dupla habilitação é bastante farta se não se consideram repercussões pedagógicas e linguísticas. Do contrário, fácil seria aprender uma nova língua sem aumentar o tempo de estudo durante a graduação. Sob raras exceções, o professor de LP e de ILE transita confortavelmente pelas duas disciplinas, a não ser se se torna convencido a complementar a carga horária reduzida na instituição em que trabalha. Contudo, antes de se valer como objeto de ensino, estamos falando de línguas distintas, condição essa que evoca aspectos sociais de identidade, de motivação, de vida, entre outros. 


\section{CONSIDERAÇÕES FINAIS}

A formação para dupla licenciatura em Letras é histórica, política e técnica. Sem criticidade sobre os arranjos sociais que imprimem novas formas linguísticas e sobre culturas que transitam numa aldeia global e tecnológica, seguida de "transformação", a formação do professor de línguas é fadada ao fracasso. A vantagem qualitativa de exposição à formação em LP é evidente, porque faz parte das identidades que constituem a maioria dos licenciandos, especialmente a linguística. Por isso, é preciso uma reformulação no currículo sustentada por novas políticas de formação docente. Não adianta ter um professor formado, mas não preparado para atuar na língua que ensinará aos alunos.

Além do investimento político, são urgentes pedagogias e características aplicadas à linguagem para a formação docente em Letras, para não entregarmos à educação básica professores que são, por lei, habilitados, mas que apresentam sérias dificuldades para o exercício de uma das línguas. O sonho do ingresso em uma graduação em Letras, pautado na expectativa positiva de intercâmbios e viagens, no conhecimento de novas culturas e na oportunidade de trabalho, deve ser visto com cautela pedagógica e não mercadológica. Aprender uma língua é algo complexo e requer sutilezas em formação profissional. Se ainda não há testes de proficiência no vestibular antes do ingresso na respectiva língua para a qual deseja se formar, a fim de se mobilizar o "aperfeiçoamento" linguístico e o aprofundamento profissional, se ainda não há um aumento de carga horária que vise à exposição à língua de aperfeiçoamento, a mudança no currículo de formação e as políticas de formação docente não podem faltar.

\section{DOUBLE DEGREE IN LANGUAGES: LANGUAGE AND PEDAGOGIC IMPLICATIONS TO TEACHER EDUCATION}

\section{RESUMO}

This study aims to problematize aspects related to obligatory double degree in Languages at Universidade Estadual de Goiás, including language and pedagogic reflections to students who are majoring in Portuguese and English. A case study, supported by a documentary research and based on Language Teacher Education theories (ALMEIDA FILHO, 2004; CELANI, 2010; 
PAIVA, 2003, 2004, 2005; QUADROS-ZAMBONI, 2015), was conducted, firstly, with pre-service language teachers of all campuses that have Language Studies. After, the specificity was restricted to a single context. During the studies, we noticed that double degree in languages promotes some (in) viabilities for the teacher education, requiring critical reflection by the institutions responsible for the elaboration of teacher training policies, so that this education can be improved.

KEYwORDs: Letras course, double degree, teacher education.

\section{LA DOBLE HABILITACIÓN EN EL CURSO DE LETRAS: IMPLICACIONES LINGÜÍSTICAS Y FORMADORAS}

\section{RESUMEN}

Este trabajo tiene el objetivo de problematizar aspectos inherentes a la doble habilitación obligatoria en el curso de Letras de la Universidad Estadual de Goiás, discutiendo sus implicaciones lingüísticas y formadoras para los futuros profesores de lengua portuguesa y extranjera (inglés). Un estudio de caso, apoyado en una investigación documental y subsidiado por teorías de formación de profesores de lenguas (ALMEIDA FILHO, 2004; CELANI, 2010; PAIVA, 2003, 2004, 2005; QUADROS-ZAMBONI, 2015). Este trabajo, inicialmente fue conducido con graduados de 2017 de todos los cursos de Letras de la UEG. Después, se restringió la especificidad a un único contexto instalado en una ciudad de Goiania. Durante los estudios, percibimos que la habilitación doble promueve algunas (in)viabilidades en su proceso de formación docente, necesitando de reflexiones críticas por parte de las instancias responsables por la elaboración de las políticas de formación, para que ese proceso formativo se perfeccione.

Palabras Clave: curso de Letras, doble habilitación, formación del profesorado.

\section{NotAS}

1. Considerando-se o contexto de pesquisa, neste texto, referimonos genericamente a línguas, fazendo alusão específica às línguas portuguesa e estrangeira (inglês) sempre que necessário 
e reconhecendo as devidas condições de sua aprendizagem e formação por estudantes brasileiros licenciandos em Letras. No entanto, também consideramos a terminologia língua estrangeira e língua inglesa quando originalmente empregada por pesquisadores, pelos participantes do estudo e/ou por documentos oficiais.

2. As Faculdades de Filosofia, Ciências e Letras, encarregadas da formação de recursos humanos para a Educação, através do Decreto Lei no 1190, deram início ao esquema “3+1", estrutura que foi mantida até os anos 60. Esse sistema acrescentava à formação de bacharéis um ano com disciplinas da área da educação, na seção de Didática, para que eles pudessem de tornar professores (GATTI, 2010).

3. Mínimo de horas obrigatórias em vigor no contexto da pesquisa, uma vez que atualmente vigora a Resolução $\mathrm{CNE} / \mathrm{CP} \mathrm{n}^{\mathrm{o}} 2$, aprovada em $1^{\circ}$ de julho de 2015.

\section{REFERÊNCIAS}

ALMEIDA FILHO, José Carlos Paes de. (Org.). O professor de língua(s) profissional, reflexivo e comunicacional. Revista Horizontes de Linguística Aplicada, Brasília, v. 4, p. 7-19, jul./dez. 2004.

ALVAREZ, Maria Luisa Ortiz Alvarez. O. O papel dos cursos de Letras na formação dos professores de línguas: ontem, hoje e sempre. In: SILVA, K. A. (Org.). Ensinar e aprender línguas na contemporaneidade: linhas e entrelinhas. Campinas: Pontes Editores, 2010. p. 235-255.

ALVES, Raphael et al. Ser ou não ser professor da educação básica? Salário esperado e outros fatores na escolha ocupacional de concluintes de licenciatura. Área ANPEC: área 13 - Economia do Trabalho. 2016. Disponível em: $<$ http://www.anpec.org.br/novosite/br/44-encontro-nacional-de-economia-trabalhos-selecionados> . Acesso em: 29 set. 2017.

ANTUNES, Irandé. Língua, texto e ensino: outra escola possível. São Paulo: Parábola, 2009.

BRASIL. Decreto ${ }^{\circ} 6.283$, de 25 de janeiro de 1934. Cria a Universidade de São Paulo e dá outras providências. Diário Oficial da União, Brasília, 
25 de janeiro de 1934. Disponível em: < http://www.leginf.usp. br/?historica=decreto-n-o-6-283-de-25-de-janeiro-de-1934>. Acesso em: 25 jun. 2016.

. Lei $\mathrm{n}^{\circ}$ 9.394, de 20 de dezembro de 1996. Estabelece as diretrizes e bases da educação nacional. Diário Oficial da União, Brasília, 23 de dezembro de 1996. Disponível em: http://www.planalto.gov.br/ccivil_03/leis/L9394. htm. Acesso em: 25 jun. 2016.

. Ministério da Educação. Secretaria de Educação Fundamental. Parâmetros curriculares nacionais: terceiro e quarto ciclos do ensino fundamental: língua portuguesa. Brasília: MEC/SEF, 1998a. 106 p. Disponível em: <http://portal.mec.gov.br/seb/arquivos/pdf/portugues.pdf>. Acesso em: 20 jun. 2017.

- Ministério da Educação. Secretaria de Educação Fundamental. Parâmetros curriculares nacionais: terceiro e quarto ciclos do ensino fundamental: língua estrangeira. Brasília: MEC/SEF, 1998b. 120 p. Disponível em: $<$ http://portal.mec.gov.br/seb/arquivos/pdf/pcn_estrangeira.pdf $>$. Acesso em: 20 jun. 2017.

.PlanoNacionaldaEducação. Brasília:SenadoFederal,UNESCO,2001. Disponível em: $<$ http://unesdoc.unesco.org/images/0013/001324/132452porb. pdf>. Acesso em: 25 fev. 2017.

. Ministério da Educação. Conselho Nacional de Educação (CNE). Secretaria de Educação Superior. Parecer CNE/CES n 492 de 3 de abril de 2001. Diretrizes Curriculares Nacionais para os Cursos de Filosofia, História, Geografia, Serviço Social, Comunicação Social, Ciências Sociais, Letras, Biblioteconomia, Arquivologia e Museologia. Brasília, DF. Disponível em: $<$ http://portal.mec.gov.br/cne/arquivos/pdf/CES0492.pdf $>$. Acesso em: 25 jun. 2016.

. Ministério da Educação. Conselho Nacional de Educação (CNE). Secretaria de Educação Superior. Resolução $C N E / C P, n .2$ de 19 de fevereiro 2002. Institui a duração e a carga horária dos cursos de licenciatura. Conselho Nacional de Educação (CNE). Brasília, DF. Disponível em: <http: // portal. mec. gov. br/ cne / arquivos / pdf/CP022002.pdf>. Acesso em: 25 jun. 2016.

. Ministério da Educação. Secretaria da Educação Básica. Orientações curriculares para o ensino médio: linguagem, códigos e suas tecnologias. Brasília: MEC/SEB, 2006. Disponível em: http://portal.mec.gov.br/seb/ arquivos/pdf/book_volume_01_internet.pdf. Acesso em: 30 maio 2017. 
- Instituto Nacional de Estudos e Pesquisas Educacionais Anísio Teixeira. Portaria Inep $n^{\circ} 260$, de 02 de junho de 2014. Diário Oficial da União, 2014. Disponível em: <http://download.inep.gov.br/educacao_superior/enade/ legislacao/2014/

diretrizes_cursos_diploma_licenciatura/diretrizes_licenciatura_letras_ portugues_ingles.pdf $>$ Acesso em: 12 abr. 2017.

. Plano Nacional de Educação 2014-2024 [recurso eletrônico]: Lei no 13.005, de 25 de junho de 2014, que aprova o Plano Nacional de Educação (PNE) e dá outras providências. - Brasília: Câmara dos Deputados, Edições Câmara, 2014. 86 p. - (Série legislação ; n. 125) Disponível em: <http://www. observatoriodopne.org.br/

uploads/reference/file/439/documento-referencia.pdf>. Acesso em: 02 jan. 2017.

BRYMAN, Alan. Quantity and quality social research. New York: Routledge, 1995.

CELANI, Maria Antonieta Alba. Perguntas ainda sem resposta na formação de professores de línguas. In: GIMENEZ, Telma; MONTEIRO, Maria Cristina de Góes. (Orgs.). Formação de professores na América Latina e transformação social. Campinas - SP: Pontes Editores, 2010. p. 57-67.

CHAGAS, Valnir. Currículo mínimo e duração do curso de Letras (Parecer $\mathrm{n}^{\circ}$ 283/62). In: Documenta n. 10. Rio de Janeiro: MEC/CFE, 1962.

GARDNER, Robert. C. Social psychology and second language learning: the role of atitudes and motivation. London: Richard Clay (The Chaucer Press) Ltd., 1985.

GATTI, Bernadete. Formação de professores no Brasil: características e problemas. Educação \& Sociedade, v. 31, n. 113, p. 1355-1379, 2010.

GIL, Antonio Carlos. Métodos e técnicas de pesquisa social. São Paulo: Atlas, 2008.

GOIÁS. Universidade Estadual de Goiás. Projeto pedagógico do curso de licenciatura em Letras. São Miguel do Araguaia: 2011.

OLIVEIRA, Hélvio Frank de. Esculpindo a profissão professor: experiências, emoções e cognições na construção das identidades docentes de licenciandos em Letras. 2013. 302 f. Tese (Doutorado em Letras e Linguística) Universidade Federal de Goiás, Goiânia, 2013. 
- Crenças sobre a profissão docente em contextos educacionais: investigações situadas. In: CONCEIÇÃO, Mariney Pereira (Org.). Letramentos, crenças de aprendizagem de línguas e inclusão social. Campinas, SP: Pontes Editores, 2016. p. 193-222.

OLIVEIRA, Hélvio Frank de; FIGUEIREDO, Francisco José Quaresma. O que o 'não' nos diz: narrativas de licenciados em Letras que não se tornaram professores. In: OLIVEIRA, Hélvio Frank de.; BICALHO, Poliene Soares dos. Santos; MIRANDA, Sabrina do Couto (Org.). Educação e diversidade: múltiplos olhares. Goiânia: Gráfica e Editora UEG, 2013. p. 117-138.

PAIVA, Vera Lúcia Menezes de Oliveira. A LDB e a legislação vigente sobre o ensino e a formação de professor de língua inglesa. In: STEVENS, Cristina Maria Teixeira; CUNHA, Maria Jandyra Cavalcanti (Orgs.). Caminhos e colheitas: ensino e pesquisa na área de inglês no Brasil. Brasília: UnB, 2003. p.53- 84 .

. Avaliação dos cursos de Letras e a formação do professor. Revista do GELNE, João Pessoa. v. 5, n. 1 e 2., p. 193-200, 2004.

. O novo perfil dos cursos de licenciatura em Letras. In: TOMICH, L. M. B. et al. (Org.). A interculturalidade no ensino de inglês. Florianópolis: UFSC, 2005. p. 345-363.

PIMENTA, Selma Garrido; LIMA, Maria Socorro Lucena. Estágio e docência. São Paulo: Cortez, 2012.

QUADROS-ZAMBONI, Alessandra da Silva. Apendicite formativa nos cursos de Letras: reflexões sobre a formação do professor de inglês. Campinas, SP: Pontes Editores, 2015.

SANTOS, Cintia Dias Rodrigues. Concepções de professores em formação sobre o ensino de gramática em língua inglesa. 2012. 123 f. Dissertação (Mestrado em Educação) - Faculdade de Ciências Humanas, Universidade Metodista de Piracicaba, Piracicaba, 2012.

SOUZA, Gilton Sampaio de et al. A formação do professor no curso de Letras: aspectos do objeto de ensino em disciplinas da área de língua portuguesa. Letras, Santa Maria, v. 22, n. 44, p. 197-211, jan./jun. 2012.

STAKE, Robert. Case studies. In: DENZIN, N. K.; LINCOLN, Y.S. (Ed.). Handbook of qualitative research. Thousand Oaks, Califórnia: Sage, 2000. p. 435-454. 
TRAVAGLIA, Luiz Carlos. Gramática e interação: uma proposta para o ensino de gramática. São Paulo: Cortez, 2009.

ZOZZOLI, Rita Maria Diniz. Professores de língua portuguesa em formação e ação: procurando escapar da transmissão de saberes. In: SILVA, K. A. et. al. (Org.). A formação de professores de línguas: novos olhares. Campinas, SP: Pontes Editores, 2012. p. 405-427. (v. 2).

Submetido em 06 de março de 2018

Aceito em 14 de julho de 2018

Publicado 30 de novembro de 2018 